\title{
Study on the development of sansheng space in pastoral areas of Inner Mongolia
}

\author{
Huan $\mathrm{Qu}^{1 *}$, and Jun $\mathrm{Ma}^{2}$ \\ Inner Mongolia University of Technology
}

\begin{abstract}
We should take the initiative to seize opportunities, scientifically respond to challenges, reasonably solve problems existing in development. effectively promote the accelerated transformation of development mode and the optimization and upgrading of industrial structure in pastoral areas of Inner Mongolia, and promote their coordinated development, innovative development, green development and modernization.By analyzing the development status of ecology, production and life in pastoral areas of Inner Mongolia, this paper finds out the problems existing in its development, and puts forward policy suggestions.
\end{abstract}

Keywords: Three living spaces; green development; Inner Mongolia Pastoral Area.

\section{Current situation of green development in pastoral areas of Inner Mongolia}

Green development in pastoral areas of Inner Mongolia has always been an important development issue concerned by the autonomous region and the whole country. This paper analyzes the current situation of green development in Inner Mongolia Pastoral Area from the ecological environment, industry and population of Inner Mongolia Pastoral Area.

\subsection{Analysis of ecological status in pastoral areas of Inner Mongolia}

\subsubsection{Analysis on the current situation of grassland quantity and quality}

The grassland in Inner Mongolia has been seriously degraded to an alarming extent. Among the available grassland area of more than 63.59 million hectares, the degraded grassland area has reached 38.67 million hectares, accounting for $60 \%$ of the available grassland. According to statistics, by the beginning of this century, the degraded area of grassland had reached $73 \%$ of the total grassland area, and the average livestock carrying capacity of grassland was 27.79 $\mathrm{mu} / \mathrm{sheep}$ unit, down $38.03 \%$ compared with the 1980 s. It is mainly reflected in the reduction of grass coverage and grass yield per unit area due to the influence of rats, pests and fire [1]. Rodent and insect pests and other bad soil layer structures and grass roots cause large-area grassland degradation and desertification, and destroy the ecological balance of grassland. It can be seen from the figure below that the overall trend of grassland rodent

"Corresponding author: 1039930437@qq.com 
damage area and grassland fire area in pastoral areas in recent ten years is an upward trend, while the grassland pest damage area has gradually eased and is in a downward trend in recent years.

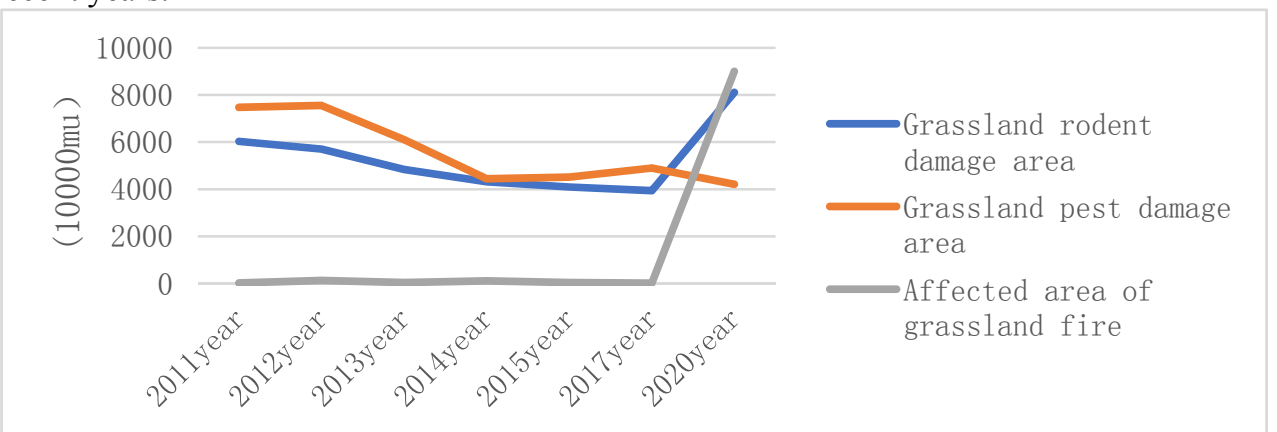

Note: data source Inner Mongolia statistical yearbook 2021 (missing data in 2016, 2018 and 2019)

Fig.1. Area affected by rats, insects and fire in Inner Mongolia Grassland.

\subsubsection{Change of ecological assets}

Ecological assets are natural assets that can provide ecological products and services for human beings. The quality of ecological assets is directly related to the supply and regulation of ecosystem and the change of cultural service value [2]. Through the calculation of ecological assets data of grassland and pastoral areas in Inner Mongolia in 2015, the area of grassland ecological assets is $436900 \mathrm{~km} 2$, accounting for about $57 \%$ of the total area of regional ecological assets; Through data analysis, taking 2000 as the dividing point, before 2000 , due to land reclamation, the area of the whole region decreased by 3 million Hm2 every five years, and grassland and pastoral areas accounted for 50\%; Since 2000, the grassland area in the whole region has hardly changed, and the grassland area in pastoral areas has decreased by $732.3 \mathrm{~km} 2$.

\subsection{Current situation of industry in pastoral areas of Inner Mongolia}

\subsubsection{Changes in stocking capacity}

The change of livestock carrying capacity reflects the production capacity of natural grassland in this area.Affected by policy support and rising prices, cattle and sheep breeding has obvious benefits, and the stock and sale of cattle have increased steadily. The slaughter of pigs and poultry increased.First, affected by drought, forage yield decreased significantly, and farmers increased their marketing to reduce costs;Second, with the implementation of the second round of grassland ecological reward and subsidy mechanism policy, all localities have increased the supervision and management of grassland livestock carrying capacity; Third, the price rise of pigs and poultry this year is also a main reason for accelerating the release of pigs and poultry. 
Table 1. Number and growth rate of livestock in 2020.

\begin{tabular}{ccc}
\hline index & 2020year & $\begin{array}{c}\text { Increase over the previous } \\
\text { year (\%) }\end{array}$ \\
\hline Total meat output (10000 tons) & 260.7 & 1.5 \\
pork & 61.4 & -1.9 \\
beef & 66.3 & 3.9 \\
mutton & 113 & 2.9 \\
poultry & 20.1 & -3.0 \\
Total number of livestock at the end of the year (10000, PCs.) & 7279.4 & 3.5 \\
pig & 534.1 & 24.3 \\
cattle & 671.1 & 7.2 \\
sheep & 6074.2 & 1.6 \\
\hline
\end{tabular}

It can be seen from table 1 that the total meat output of Inner Mongolia Autonomous Region in 2020 was 2.607 million tons, an increase of $1.5 \%$ over 2019. Except for the decline of pig and poultry meat output, the other output and the total number of livestock showed an upward trend. Generally speaking, the improvement of Urbanization level increased the difficulty of reconciliation between traditional animal husbandry and modern production, It is not only reflected in the change of livestock carrying capacity, but also reflects the lack of characteristics of animal husbandry development management and weak ecological carrying capacity in pastoral areas, which has a certain impact on animal husbandry development.

\subsubsection{Current situation of industrial and agricultural production}

Agriculture and animal husbandry is the basic industry in Inner Mongolia Pastoral Area.According to the international measurement indicators of agricultural development level, developed countries account for $50 \%$ or more. According to relevant statistics, the highest value in China in previous years is $32 \%$. Among them, the contribution of Inner Mongolia can reach 50\%, and the proportion of pastoral areas is larger.The added value of agriculture, forestry, animal husbandry and fishery has been growing positively in recent ten years, reaching 167.771 billion yuan by 2017 , the highest value over the years. The output of main crops basically kept rising.In recent 10 years, the secondary industry in pastoral areas has developed rapidly, including processing industry and mining industry. According to the data of the National Bureau of statistics, compared with 2019, most of the industrial output, such as crude oil, natural gas, coke and steel, has increased positively, and only a few of the industrial output is flat or reduced, such as the output of raw salt, soda ash and ethylene.The output of the mining industry also increased steadily from 2011 to 2016.

\subsection{Population change in pastoral areas}

The change of population in pastoral areas reflects the economic development level of pastoral areas to a certain extent. According to the data from Inner Mongolia statistical yearbook, comparing the data of pastoral population and urban population in 2019 and 2020, the urban population is 16.215 million. The rural population is 7.813 million; The urbanization rate of permanent residents reached $67.5 \%$, with a birth rate of $8.3 \%$; The mortality rate is $5.9 \%$ and the natural population growth rate is $2.5 \%$. Generally speaking, the "grazing prohibition policy" has continuously improved the urbanization level of the permanent population in Inner Mongolia Autonomous Region, reduced the population in pastoral areas, and deepened the aging degree of herdsmen. 


\section{Problems of green development in pastoral areas of Inner Mongolia}

\subsection{The quantity and quality of grassland in pastoral areas of Inner Mongolia are decreasing, the grass and livestock are unbalanced, and the output value of animal husbandry needs to be improved}

The problem of ecological balance between grassland and livestock is still significant. $70 \%$ of grassland in Inner Mongolia pastoral area exceeds the actual livestock carrying capacity. The allocation of agricultural and animal husbandry resources is unbalanced and lacks an effective combination model.According to the statistical yearbook, the total grassland area in Inner Mongolia is 78804.48 thousand hectares, and the grassland area is still decreasing in the past 20 years. The main reasons are: the development of urbanization, the development of industry and mining industry, etc;Affected by human and natural factors, the degraded area of grassland is increasing year by year, resulting in the decline of grassland quality.

\subsection{Deterioration of ecological environment and decline of ecological function in grassland and pastoral areas}

Agriculture and animal husbandry is the basic industry in pastoral areas of Inner Mongolia.According to the international measurement indicators of agricultural development level, developed countries account for 50\% or more. According to relevant statistics, the highest value in China in previous years is $32 \%$, which will drop to $29 \%$ in 2018 . Among them, the contribution of Inner Mongolia can reach 50\%, and the proportion of pastoral areas is larger. The added value of agriculture, forestry, animal husbandry and fishery has been growing positively in recent ten years. In recent 10 years, the secondary industry in pastoral areas has developed rapidly, including processing industry and mining industry. The output of the mining industry also increased steadily from 2011 to 2016.

\subsection{Outflow of labor force and reduction of labor level}

The unreasonable population structure in pastoral areas of Inner Mongolia, The education level and skill level of the population in pastoral areas are low,And the slow rate of income increase, affect the income of herdsmen, and the characteristics of population aging are obvious . Therefore, the level of education, health and management in some rural pastoral areas is also significantly declining, exposing the problems of low efficiency and high cost. With the development of science and technology, the vocational skills of rural pastoral workers can not keep up with the requirements of the modernization of grassland animal husbandry.

\section{Suggestions on green development in pastoral areas}

\subsection{Optimal construction of ecological pastoral areas}

Protecting and restoring ecology is the top priority in the construction of ecological pastoral areas, which mainly focuses on two aspects: first, optimizing and adjusting the balance between grass and livestock, and evaluating the production and ecological status of grassland through grassland dynamic monitoring; The second is Grassland quality and important ecological space protection. It is of great significance to delimit and strictly abide by the red 
line of ecological protection, promote natural resource protection and ecological restoration, and optimize the pattern of land and space development.

\subsection{Development of animal husbandry and rational exploitation of mineral resources}

Inner Mongolia Autonomous Region is rich in mineral resources .According to the relevant arrangements of the central government, since 2016, the autonomous region has successively carried out special actions such as implementing the rectification of the central environmental protection inspector and the special rectification of violations and violations in the field of coal resources, and achieved positive results, but there are still some weaknesses .Main measures: strictly control new mineral resources development projects on the grassland;Strictly regulate the existing mineral resources development projects on the grassland;Strictly supervise the development of grassland mineral resources; We will severely crack down on the illegal occupation of grasslands in the development of mineral resources.

\subsection{Attract local talents to return home and build a team of animal husbandry support talents}

The construction of talent team has always been an important factor in the development of rural industry. Actively build a new pattern of talent cultivation and attraction policies, continue to expand the Rural Revitalization talent team, and actively give full play to the leading and exemplary role of local sages and squires in industrial development and rural governance, so as to make them become the backbone of promoting rural development and progress. At the same time, build a scientific and technological talent team with reasonable structure to support agriculture and animal husbandry, and improve the relevant management system and assessment system, so as to make it an important promoter of professional and information management in the process of industrial development in rural pastoral areas.

\section{Conclusion}

The green development of pastoral areas in Inner Mongolia is inseparable from the effective coordination between the three living spaces. It not only promotes the economic development of pastoral areas, but also plays an important role in ecological protection.

\section{Acknowledgement}

Fund Project: National Natural Science Foundation of China (No.: 71864026); Natural Science Foundation of Inner Mongolia Autonomous Region (No.: 2018ms07004)

\section{References}

1. Miao Jing, Gai Zhiyi Thoughts on the evolution of industrial structure of 33 typical animal husbandry banners (cities) in Inner Mongolia [J]Inner Mongolia Social Sciences (Chinese version), 2018,39 (03): 182-188

2. Zhang Hao Study on sustainable development of grassland animal husbandry in Inner Mongolia [D] Northwest University of agriculture and forestry science and technology, 2019 DOI:10.27409/d.cnki. gxbnu. 2019.000140. 